\title{
NUTRIENT TRANSFER IN VESICULAR-ARBUSCULAR MYCORRHIZAS: A NEW MODEL BASED ON THE DISTRIBUTION OF ATPases ON FUNGAL AND PLANT MEMBRANES*)
}

\author{
F.A. SMITH \\ Department of Botany, The University of Adelaide, South Australia, 5005, \\ Australia \\ S.E. SMTH \\ Department of Soil Science, The University of Adelaide, South Australia, 5005, \\ Australia
}

\begin{abstract}
In this paper we review the membrane transport processes that are involved in the transfer of mineral nutrients and organic carbon between the symbiotic partners in mycorrhizas. In particular, we reassess the prevailing hypothesis that transfer in vesicular-arbuscular (VA) mycorrhizas occurs simultaneously and bidirectionally across the same interface and that arbuscules are the main sites of transfer.

Using cytochemical techniques, we and our collaborators have reexamined the distribution of ATPases in the arbuscular and intercellular hyphal interfaces in VA mycorrhizas formed between roots ofAllium cepa (onion) and the fungus Glomus intraradices. The results showed that $\mathrm{H}^{+}$-ATPases have different localisation on plant and fungal membranes in arbuscular and hyphal interfaces (Gianinazzi-Pearson et al. 1991). While some arbuscular interfaces had $\mathrm{H}^{+}$-ATPase activity on both fungal and plant membranes, in most cases the fungal membrane lacked this activity. In contrast, the plasma membranes of intercellular hyphae always had $\mathrm{H}^{+}$ -ATPase and the adjacent root cells did not. This suggests that the different interfaces in a VA mycorrhiza may have different functions.

We propose that passive loss of $\mathrm{P}$ from the arbuscules is associated with active uptake by the energised (ATPase-bearing) plant membrane and that passive loss of carbohydrate from the root cells is followed by active uptake by the intercellular hyphae. If this model is correct, then variations in "mycorrhizal efficiency" (i.e. the extent to which mycorrhizal plants grow better than non-mycorrhizal controls) might be determined by differences in the numbers of active arbuscules as a proportion of the total fungal biomass within the root.

As a first step towards investigating this possibility, we have developed methods for measuring the surface areas of arbuscular and hyphal interfaces in different fungus-host combinations, Glomus spp./ Allium porrum (leek). We have also measured fluxes of $\mathrm{P}$ from fungus to plant and have been able to partition these between the arbuscular and total (arbuscular plus hyphal) interfaces. The implications of this work, and suggestions for future investigations of the molecular mechanisms involved in nutrient transfer in mycorrhizas, are discussed.
\end{abstract}

Key words: Mycorrhizas/Glomus intraradices/ATPases/Allium cepa.

\footnotetext{
*)Paper presented at the Second Symposium on Biology and Biotechnology of Mycorrhizae and Third Asian Conference on Mycorrhizae (ACOM III), 19-21 April, Yogyakarta, Indonesia.
} 


\section{BIOTROPIA No. 8, 1995}

SMITH, S.E., S. DICKSON, C. MORRIS and F.A. SMITH. 1994b. Transfer of phosphate from fungus to plant in VA mycorrhizas: calculation of the area of symbiotic interface and fluxes of $\mathrm{P}$ from two different fungi to Allium porrum. New Phytologist. In press.

SMITH, S.E. and F.A. SMITH. 1990. Structure and function of the interfaces in biotrophic symbioses. New Phytologist, 114, 1-38.

SMITH, S.E. and F.A. SMITH. 1994. Membranes in mycorrhizal interfaces: specialised functions in symbiosis. In: Membranes - Specialised Functions in Plant Cells. Ed. by M. Smallwood and D. Bowles, JAI Press Inc. (in press).

TESTER, M. 1990. Plant ion channels: whole cell and single channel studies. New Phytologist, 114, 305-340. 


\section{INTRODUCTION}

Transfer of nutrients is of central importance in the functioning of the very widespread symbioses between mycorrhizal fungi and their host plants. The host gains mineral nutrients (e.g. phosphate and zinc), and in all mycorrhizas except orchid mycorrhizas the fungus gains carbohydrate. This two-way transfer occurs across interfaces which comprise the membranes of both organisms and an apoplastic region between them. The interfacial apoplast may contain considerable amounts of wall or wall-derived material, which varies according to the type of mycorrhiza and the particular interface (Smith and Smith 1994). In ectomycorrhizas, the interface is entirely intercellular (extracellular), whereas in some endomycorrhizas (e.g. ericoid mycorrhizas), the interface is virtually entirely intracellular. Other endomycorrhizas (e.g. vesicular-arbuscular mycorrhizas) have both an intercellular interface - where the fungus penetrates between cortical cells, and an intracellular interface - where the fungus penetrates the cell walls of its host and develops arbuscules.

In all cases, the interface has a restricted volume. It is isolated from the external environment, and membrane transport processes in both organisms will control the physico-chemical conditions in the apoplast and hence the overall transport of solutes from one organism to the other. Fig. 1 summarises the uptake and transfer of nutrients in all mycorrhizas except orchids. As well as emphasising phosphate $(\mathrm{P})$ and

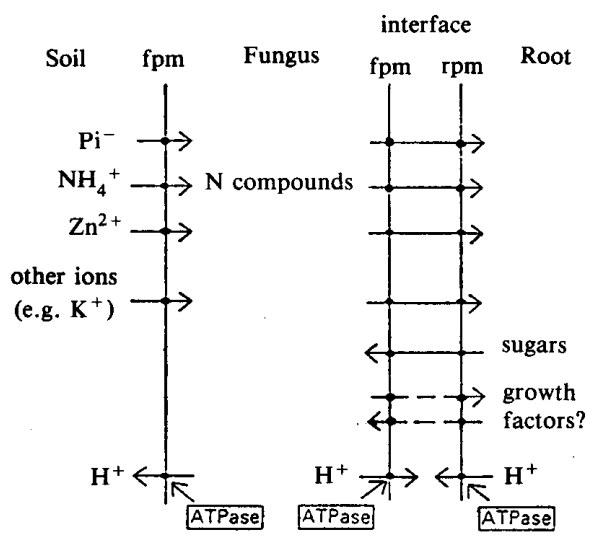

Figure 1. Transfer of mineral nutrients and carbohydrates (sugars) in mycorrhizas (excluding orchids). With the exception of $\mathrm{H}^{+}$-ATPases (see text), the mechanisms of membrane transport are not specified, fpm: fungal plasma membrane; rpm: root plasma membrane; $\mathrm{Pi}$ : inorganic phosphate. 
zinc ( $\mathrm{Zn})$, it shows that other mineral nutrients can be transferred from soil to the host via the fungus. In the case of $\mathrm{NH}_{4}{ }^{+}$, there is conversion to organic $\mathrm{N}$ compounds and subsequent transfer of some of these across the interface. The transfer of sugars to the fungus is shown in Fig. 1, and also the possible transfer of "growth factors" i.e. phytohormones, vitamins etc. Finally, Fig. 1 shows the presence of $\mathrm{H}^{+}$-transporting ATPases that are present in the functional plasma membranes of all fungal and plant cells. These "energise" the membranes both electrically, via the generation of electric potential differences (PDs), and chemically via the development of $\mathrm{pH}$ differences, and so allow selective transport of other solutes. For example, phosphate and sugars are transported into fungal and plant cells by diferrent transport proteins which catalyse co-transport of phosphate or sugar with $\mathrm{H}^{+}$(not shown in Fig. 1, for simplicity). Other types of transport proteins are "channels" which can open and close in response to various signals at the plasma membrane, including changes in PDs and $\mathrm{pH}$. For a general discussion of interfaces and transport in mycorrhizas, see Smith and Smith $(1990,1994)$. Tester (1990) describes factors that control the operation of channels.

\section{MEMBRANE TRANSPORT AND ATPases IN VA MYCORRHIZAS}

For VA mycorrhizas, the prevailing hypothesis has been that transfer of nutrients and carbohydrates occurs bidirectionally and simultaneously across the same interface and that the arbuscules, having large surface-to-volume ratio, are important as the main site of transfer. It has been suggested in the past - and sometimes even now that- $\mathrm{P}$ transfer can be explained by breakdown (digestion) of arbuscules, releasing $\mathrm{P}$ to the host. However, calculations by Cox and Tinker (1976) showed that this would be far too slow the account for the fluxes of $\mathrm{P}$ across the interface. To make these calculations, Cox and Tinker (1976) measured surface areas of arbuscules in the Glomus mosseae/Allium cepa (onion) symbiosis using electron microscopy and image analysis, the amount of infection and the total numbers of arbuscules per unit length of root. They also estimated the life- span of the arbuscules (about 4 days), their $\mathrm{P}$ content and the inflow of $\mathrm{P}$ - i.e. the uptake of $\mathrm{P}$ to the host per unit length of root. In this way, they showed that the $\mathrm{P}$ that could be released by digestion was about 100 times too small for the actual P flux; hence continuing transfer from living arbuscules is required. This is an important conclusion, and the calculated value for the P flux - $13 \mathrm{nmol} \mathrm{m}$ (arbuscular surface area $)^{-2 s-1}$-is also important since it is similar to values for uptake of $\mathrm{P}$ into cells by active transport (i.e. by $\mathrm{H}^{+}-\mathrm{P}$ co-transport), but much larger than ty- 
pical values for efflux of P. An important question thus becomes: what is the mechanism for release of $\mathrm{P}$ from the fungus? This issue is discussed by Smith et al. (1994a).

The hypothesis of simultaneous two-way transport of $\mathrm{P}$ and sugar in VA my corrhizas is summarised in Fig. 2. Details of co-transport and passive transport are shown. The hypothesis has been supported by the cytochemical demonstration of ATPases on both fungal and plant plasma membranes in the arbuscular interface (Marx et al. 1982), but does not take into account the potential role of the intercellular fungal hyphae in transport processes (Smith and Dickson 1991). Likewise, the possible role of the intercellular interface was not considered by Cox and Tinker (1976).

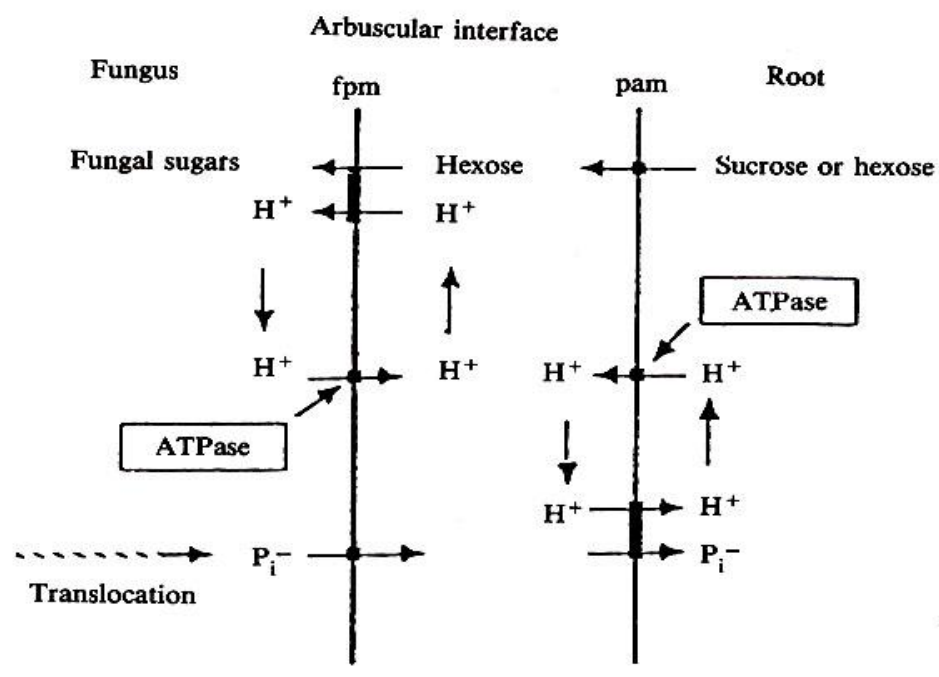

Figure 2. Diagrammatic representation of the distribution of $\mathrm{H}^{+}$-ATPases and associated transport processes in VA mycorrhizas that would result in bidirectional transfer of sugar and phosphate across the same arbuscular interface. Based on Figure 7 of Gianinazzi-Pearson et al. (1991). pam: periarbuscular (plasma) membrane of the root cortical cells. 


\section{SPATIAL SEPARATION OF TRANSPORT?}

Gianinazzi-Pearson et al. (1991) re-examined the distribution of ATPases in the arbuscular and intercellular (hyphal) interfaces in VA mycorrhizas formed between roots of Allium cepa (onion) and Glomus intraradices. The cytochemical methods were similar to those used by others: they involved the deposition of lead phosphate at sites of ATPase activity and the use of inhibitors (e.g. vanadate and molybdate) to distinguish $\mathrm{H}^{+}$-ATPases likely to be involved in active membrane transport from other enzymes with ATP-hydrolysing ability. The results showed that $\mathrm{H}^{+}$-ATPases have different localisation on plant and fungal membranes in arbuscular and hyphal interfaces (Gianinazzi-Pearson et al., 1991). While some arbuscular interfaces had $\mathrm{H}^{+}$-ATPase activity on both fungal and plant membranes, in most cases the fungal membrane lacked this activity. In contrast, the plasma membranes of intercellular hyphae always had $\mathrm{H}^{+}$-ATPase and the adjacent root cells did not.

These results suggest that the different interfaces in a VA mycorrhiza may have different functions (Fig. 3). The arbuscules may indeed play a major role in $\mathrm{P}$ transfer. Passive $\mathrm{P}$ loss from the fungus to the inter facial apoplast would be associated with active uptake $\left(\mathrm{H}^{+}-\mathrm{P}\right.$ co-transport) by the energised (ATPase-bearing) plant membrane. Reabsorption of $\mathrm{P}$ from the interfacial apoplast by the fungus may be reduced in the arbuscules, because the fungal membrane frequently appears to lack ATPase activity and hence the capacity for active uptake. These

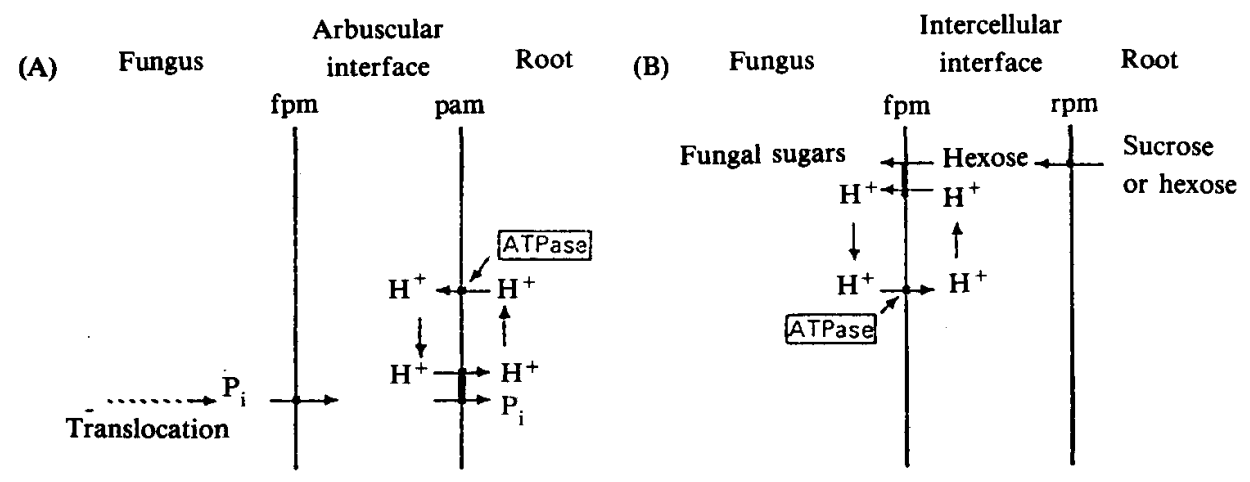

Figure 3. Spatial separation of transfer in VA mycorrhizas. A: passive loss of $\mathrm{P}$ from the fungus and active uptake $\left(\mathrm{H}^{+}\right.$-phosphate co-transport) across the energised periarbuscular membrane. $\mathrm{B}$ : passive loss of sugar to the intercellular apoplast and active uptake $\left(\mathrm{H}^{+}{ }^{+}\right.$-hexose co-transport) across the energised hyphal plasma membrane. Based on Figure 7 of Gianinazzi-Pearson et al. (1991). 
processes would result in net transfer of $\mathrm{P}$ from fungus to plant. We have shown that transfer of $\mathrm{P}$ between the symbionts occurs at rates consistent with high passive efflux from the fungus and active uptake by the plants (Smith et al. 1994a \& b). Gianinazzi-Pearson et al. (1991) propose that the intercellular hyphae (but not the arbuscules) may be responsible for carbohydrate transfer from plant to fungus. In this case, passive loss of carbohydrate from the root cortical cells to the intercellular apoplast would be followed by active uptake by the fungal hyphae. As far as we are aware, the proposal that transfers of $\mathrm{P}$ and carbohydrate are spatially separated had not been made previously.

\section{ARBUSCULES AND VA MYCORRZHIZAL "EFFICIENCY"}

An attraction of this new model is that variations in mycorrhizal "efficiency" (i.e. the extent to which mycorrhizal plants grow better than non-mycorrhizal controls) might be explained by differences in the numbers or size of metabolically active arbuscules as a proportion of the total fungal biomass within the root. Without arbuscules, the fungus would be essentially a parasite, draining carbohydrate from its host but giving no phosphate in exchange. It is well known that mycorrhizal "efficiency" does vary in different fungus/host combinations, or under different environmental conditions, but there has been little attempt to correlate these variations with numbers of arbuscules or their activity. One reason is the difficulty of measuring numbers and surface areas of arbuscules, and length and surface area of intercellular hyphae, rather than just taking the length or percent of the root that contains fungus as a measure of infection.

In order to remedy this deficiency, we have developed an updated version of the methods used by Cox and Tinker (1976), including computer-aided image analysis techniques and the use of nitroblue tetrazolium to distinguish metabolically active fungal tissues from the total fungal biomass (Smith and Dickson 1991). By means of a size facility in the program, it is possible to distinguish between intercellular hyphae and arbuscules. Table 1 shows data for Allium porrum infected by Glomus sp. 'City Beach' (WUM16). Percentage infection was obtained conventionally and the areas of interface obtained by image-analysis. Details for the experiment and methods are given by Smith and Dickson (1991) and Smith et al. (1994b). Table 1 shows that the surface area of metabolically active arbuscules per metre of root declined with time, while that of hyphae increased. After 63 days, the hyphae had the larger surface area, illustrating the danger of ignoring them as a site of nutrient transfer, irrespective of what model is adopted.

Table 2 shows the inflows of $\mathrm{P}$ (i.e. amounts of $\mathrm{P}$ taken up per metre of root length) into non-mycorrhizal and mycorrhizal plants, with the amount taken into 
Nutrient transfer in vesicular-arbuscular mycorrhizas - F.A. Smith and S.E. Smith

Table 1. Allium porrum infected with Glomus 'City Beach'. Percentages of the root length infected, and areas of arbuscular and hyphal interface infected, at three harvest times

\begin{tabular}{ccccc}
\hline \hline $\begin{array}{c}\text { Harvest time } \\
\text { (days) }\end{array}$ & $\begin{array}{c}\text { Infection } \\
(\%)\end{array}$ & arbuscules & $\begin{array}{c}\text { Interface area: } \mathrm{m}^{2} \mathrm{~m}^{-1} \text { (root) } \times 10^{-3} \\
\text { hyphae }\end{array}$ & total \\
\hline 21 & $63.5 \pm 4.1$ & 2.33 & 0.31 & 2.64 \\
42 & $68.8 \pm 1.9$ & 2.65 & 0.99 & 3.64 \\
63 & $82.1 \pm 3.4$ & 0.44 & 0.89 & 1.33 \\
\hline
\end{tabular}

the latter via the fungus calculated by subtraction. We are aware that this calculation, which assumes that fungal infection does not affect $\mathrm{P}$ uptake by the host, may produce errors, but this possibility has been ignored in our calculations. Table 2 shows that inflow of $\mathrm{P}$ decreased with time, particularly in non-mycorrhizal plants. Table 3 shows the fluxes of $\mathrm{P}$ across the interfaces, as obtained by dividing the inflows (Table 2) by the average surface areas obtained from Table 1 . The increasing divergence with time between the values that were obtained assuming that the flux occurred 1) only across the arbuscular interface and 2) across both arbuscules and intercellular hyphae reflects the increasing contribution of the latter to the total surface area. The range of values in Table 3 (3.7-12.8 nmol m $\mathrm{m}^{-2}{ }^{1}$ ) agrees quite well with the single value of nmoll m $\mathrm{m}^{-2}$ that was calculated by Cox and Tinker (1976).

Table 2. Inflows of phosphate into nonmycorrhizal $(-\mathbf{M})$ and mycorrhizal $(+\mathbf{M})$ Allium porrum, with inflows via fungus calculated by subtractions

\begin{tabular}{cccc}
\hline $\begin{array}{c}\text { Growth period } \\
\text { (days) }\end{array}$ & $-\mathrm{M}$ & $\begin{array}{c}\text { Inflow: pmol } \mathrm{m}^{-1} \text { (root) } \mathrm{s}^{-1} \\
+\mathrm{M}\end{array}$ & via fungus \\
\hline $0-21$ & 18.0 & 33.0 & 15.0 \\
$21-42$ & 2.7 & 25.0 & 22.3 \\
$42-63$ & 2.9 & 12.0 & 9.1 \\
\hline
\end{tabular}

Table 3. Fluxes of phosphate from fungus to Allium porrum. Values are obtained by dividing inflow (Table 2) by average areas of interface between two harvests (from Table 1.). Assumption (1): flux only across arbuscular interface; (2): flux across arbuscular and intercellular interfaces

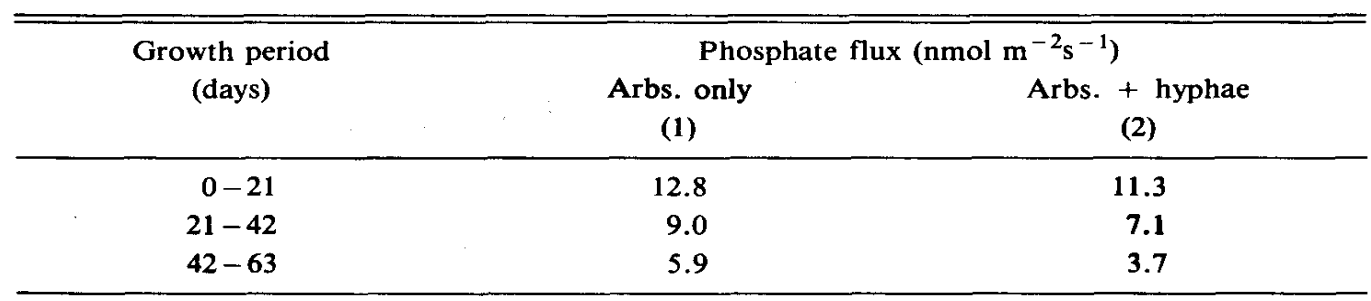


Although these results show that it is possible to make separate calculations for influx of $\mathrm{P}$ across the arbuscular interface and the total interface, they do not by themselves answer the question of whether the arbuscular interface alone is responsible for $\mathrm{P}$ transfer. To do this, it will be necessary to attempt to correlate $\mathrm{P}$ transfer with arbuscular surface area, e.g. in comparison with the total fungal biomass within the root. Results that we have obtained so far suggest that where different VA mycorrhizal fungi infect the same host species, there is no simple correlation. Table 4 shows again the results for Allium porrum infected by Glomus sp. 'City Beach' over 21-42 days of growth and compares them with results for Allium porrum/Glomus mosseae obtained at the same time and under the same conditions (Smith and Dickson 1991; Smith et al. 1994b). G. mosseae produced a slightly larger \% infection but a slightly smaller inflow of $\mathrm{P}(19.0$ compared to $22.3 \mathrm{pmol} \mathrm{m}^{-1} \mathrm{~s}^{-1}$ )- The areas of interfaces with $G$. mosseae were more than twice that with G. sp. 'City Beach', and the flux of P via mosseae was accordingly much smaller than with G. sp. ' City Beach', whether calculated using the area of arbuscular interface or the total interface. These results show that G. sp. 'City Beach' loses P faster on a surface area basis. There are several possible explanations including not only differences in numbers of membrane transport proteins at the interface but also different rates of translocation of $\mathrm{P}$ through the fungi or different rates of uptake from the soil which could in turn be associated with different lengths of external hyphae. To pursue further the question of the role of the arbuscule as the sole location of $\mathrm{P}$ transfer in comparison with that of the intercellular hyphae (or total interface) as the location of exchange of carbohydrate, it will be necessary to do more sophisticated experiments with more fungus/host combinations. The use of VA mycorrhizas in which development of arbuscules is suppressed will be particulary valuable.

Table 4. Comparison of Allium porrum infected by Glomus 'City Beach' or $G$. mosseae, after $21-42$ days of growth

\begin{tabular}{|c|c|c|c|}
\hline Parameter & & G. 'City Beach' & G. mosseae \\
\hline$\%$ infection & & 66 & 75 \\
\hline $\begin{array}{l}P \text { inflow via fungus } \\
\left.\text { (pmol } \mathrm{m}^{-1} \mathrm{~s}^{-1}\right)\end{array}$ & & 22.3 & 19.0 \\
\hline $\begin{array}{l}\text { Area of interface: } \\
\qquad\left(\mathrm{m}^{2} \mathrm{~m}^{-1} \times 10^{-3}\right)\end{array}$ & $\begin{array}{l}\text { Arbuscules: } \\
\text { Arbs. and hyphae: }\end{array}$ & $\begin{array}{l}2.5 \\
3.1\end{array}$ & $\begin{array}{l}5.9 \\
7.0\end{array}$ \\
\hline 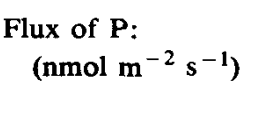 & $\begin{array}{l}\text { Arbuscules: } \\
\text { Arbs. and hyphae: }\end{array}$ & $\begin{array}{l}9.0 \\
7.1\end{array}$ & $\begin{array}{l}3.2 \\
2.7\end{array}$ \\
\hline
\end{tabular}




\section{CONCLUSIONS}

In this paper we have reviewed briefly the mechanisms for transfer of nutrients in mycorrhizas - mainly VA mycorrhizas - and have then proceeded to re-evaluate the sites of nutrient transfer, particularly the question of whether simultaneous bidirectional transfer occurs in arbuscules. We suggest that this may not be the case, and this in turn has led us to quantify the development of the arbuscular interface vis-a-vis the total interface and to attempt to calculate $P$ fluxes across both interfaces. As well as pursuing this approach further, we are starting to attempt to identify the molecular mechanisms for transport at the interface and also to measure the physico-chemical conditions there, including the ionic conditions in the apoplast. In this way we hope that the control of nutrient transfer and its role in determining "mycorrhizal efficiency" will be better understood.

\section{ACKNOWLEDGEMENTS}

We thank our collaborators, particularly Vivienne Gianinazzi- Pearson, Silvio Gianinazzi, Sandy Dickson, Christina Morris, Mark Tester and Rob Reid for all their help in discussions and experiments. Funding came from the Australian Research Council, an INRA international collaborative research program and The University of Adelaide.

\section{REFERENCES}

Cox, G. and P.B. TINKER. 1976. Translocation and transfer of nutrients in vesicular-arbuscular mycorrhizas. I. The arbuscule and phosphorus transfer: a quantitative ultrastructural study. New Phytologist, 77, 371-378.

GiANINAZZ-PEARSON, V., S.E., SMITH, S. GIANINAZZ and F.A. SMITH. 1991. Enzymatic studies on the metabolism of vesicular-arbuscular mycorrhizas $\mathrm{V}$. Is $\mathrm{H}^{+}$-ATPase a component of ATP hydro-lysing enzyme activities in plant/fungus interfaces? New Phytologist, 117, 61-74.

MARX, C., J., DEXHEIMER, V. GIANINAZZ-PEARSON and S. GIANINAZZ. 1982. Enzymatic studies on the metabolism of vesicular-arbuscular mycorrhizas IV. Ultracytoenzymological evidence (AT-Pase) for active transfer processes in the host-arbuscular interface. New Phytologist, 90, 37-43.

SMITH, F.A., S., DICKSON, C., MORRIS, R.J., REID, M., TESTER and S.E., SMITH. 1994a. Phosphate transfer in VA mycorrhizas: special mechanisms or not? Proceedings of the 4th International Symposium on the Structure and Function of Roots. In press.

SMITH, S.E. and S. DICKSON. 1991. Quantification of active vesicular-arbuscular mycorrhizal infection using image analysis and other techniques. Australian Journal of Plant Physiology, 18, 637-648. 